\section{$\underset{\substack{\text { hommes } \\ \text { \& migrations }}}{ }$}

\section{Hommes \& migrations}

Revue française de référence sur les dynamiques

migratoires

$1290 \mid 2011$

Travailleurs sociaux et migrations

\title{
Forum social mondial 2011
}

La cause des migrants débattue à Dakar

\section{Emmanuelle Bouilly}

\section{Q OpenEdition \\ 1 Journals}

\section{Édition électronique}

URL : http://journals.openedition.org/hommesmigrations/758

DOI : 10.4000/hommesmigrations.758

ISSN : 2262-3353

\section{Éditeur}

Musée national de l'histoire de l'immigration

\section{Édition imprimée}

Date de publication : 1 mars 2011

Pagination : 131-133

ISSN : 1142-852X

\section{Référence électronique}

Emmanuelle Bouilly, «Forum social mondial 2011 », Hommes \& migrations [En ligne], 1290 | 2011, mis en ligne le 29 mai 2013, consulté le 22 septembre 2020. URL : http://journals.openedition.org/ hommesmigrations/758; DOI : https://doi.org/10.4000/hommesmigrations.758

Ce document a été généré automatiquement le 22 septembre 2020.

Tous droits réservés 


\title{
Forum social mondial 2011
}

\author{
La cause des migrants débattue à Dakar
}

Emmanuelle Bouilly

"La migration est à l'honneur à l'occasion de ce FSM en terre africaine", s'enthousiasmait le Secours catholique à l'ouverture du $11^{\mathrm{e}}$ Forum social mondial (FSM) qui s'est tenu du 5 au 11 février à Dakar. D'une acuité certaine dans un pays hôte qui a récemment signé des accords de réadmission et de gestion concertée des flux migratoires, la thématique des migrations a été au cœur du FSM - conformément à la volonté de ses organisateurs et de la commission diasporaet migration. Diverses manifestations ont rythmé l'événement: proclamation de la Charte mondiale des migrants (2-4 février), arrivée des caravanes sous-régionales et marche d'ouverture sous les bannières "Liberté de circulation et d'installation pour tous" et "Régularisation de tous les sans-papiers" (5-6 février), marche pour la liberté de circulation des peuples assortie d'un sit-in devant les bureaux de Frontex (10 février), assemblée de convergence pour la liberté de circulation et assemblée du collectif Des ponts pas des murs DPPDM (11 février). Attestent également l'importance des migrations dans ce FSM les 70 activités autogérées consacrées à cet enjeu.

\section{Tenir les ateliers ! Désordre logistique et dynamiques de l'entre-soi}

2 Un programme riche qui a pourtant été perturbé. L'accord conclu entre l'université de Dakar et le comité local d'organisation qui octroyait salles de cours et espaces verts au forum n'a pas survécu à la prise de fonction d'un nouveau recteur. S'en sont suivis d'importants problèmes logistiques entraînant le report ou l'annulation de certains ateliers et la diffusion tardive du programme. Les activités autogérées ont largement pâti de ce revers. Leur lancement, le 7 février, baptisé “Journée de l'Afrique et de la diaspora", s'est fait sans que le village diaspora et migration ait été installé. Les responsables d'ateliers ont alors tenté de pallier la désorganisation en bricolant ici ou là des espaces de discussion et en distribuant affiches et flyers pour informer les 
participants. Courriels et appels téléphoniques ont soutenu ce dispositif improvisé de communication.

3 De fait, les acteurs les moins dotés en ressources et capitaux - social, militant, économique ou scolaire - n'ont pu accéder à l'information, exclus des supports et circuits de diffusion. La désorganisation a favorisé les réseaux d'interconnaissance et les dynamiques de l'entre-soi, certains ateliers ressemblant davantage à des réunions de travail entre partenaires qu'à des espaces de rencontre et de débat. Les efforts déployés en amont par la commission diaspora et migration pour intégrer les organisations communautaires de base dans le processus du FSM ont été contrariés. On a ainsi rencontré des jeunes rapatriés d'Espagne venus animer un atelier sur leur expérience migratoire dans un amphithéâtre qu'ils pensaient leur être réservé. Attendant que l'orateur à la tribune les invite à venir parler, ils assistaient sans le savoir à une conférence de Samir Amin. Pour anecdotique qu'il soit, cet exemple interroge les savoir-faire et capitaux qui conditionnent la participation à ce type d'événement.

\section{Débattre et témoigner des migrations : acteurs, conceptions et modes d'action pluriels}

4 Un large panel d'acteurs a investi les débats sur les migrations : association de défense des droits de l'homme, associations confessionnelles, églises, ONG de développement, syndicats, collectifs de soutien ou de victimes... Au sein de ce champ multiorganisationnel circulent diverses conceptions ou représentations des enjeux migratoires et des actions à entreprendre. Une pluralité qui tient à la nature et à l'histoire des organisations, à leurs missions - cibles, savoir-faire et domaines d'intervention - aux trajectoires de leurs militants mais aussi à la nature pluridimensionnelle et enchâssée des enjeux migratoires.

\section{Droit-s ou développement ? Plaidoyer ou aide?}

5 En schématisant, on peut sérier les positions le long d'un axe composé de deux pôles : le premier représenté par une "approche droits" qui appelle des actions de plaidoyer, le second, "une approche développement" qui implique des aides-projets. Alors que les premiers s'engagent, par exemple, pour la défense des droits des migrants, l'application des principes de libre circulation et d'installation ou la fermeture des centres de rétention, les seconds entreprennent des actions d'aide aux migrants ou des projets de codéveloppement.

6 Chacune de ces approches représente une facette de la "cause des migrants", incarne différentes conceptions des enjeux migratoires et endosse des modes singuliers de militantisme et de légitimité à parler "au nom de". Ces approches ne sont évidemment pas exclusives l'une de l'autre. Sur la question des liens entre migration et développement, on a vu des organisations souscrire avec le CRID et le collectif DPPDM à "la lutte contre les accords qui conditionnent l'aide au développement aux contrôles migratoires", et animer des ateliers de "sensibilisation sur les dangers du parcours des migrants", de "promotion des bonnes pratiques en matière de co-développement" ou " 
d'alternatives économiques au départ" fixant les migrants dans leur pays; là où certains voient des positions inconciliables.

\section{Migrants : témoins, acteurs ou victimes ?}

7 Autre polémique : la place réservée aux migrants dans le FSM et le rôle joué par leurs nombreux témoignages, spontanés ou programmés. La signification de ces témoignages n'est pas univoque. En tant que "dispositifs de sensibilisation", ils suscitent ici ou là-bas des émotions qui peuvent permettre de rallierr des soutiens et de lever des fonds. Témoins perçus comme authentiques et incontestables, les migrants sont alors confinés à un rôle passif, spectateurs des débats qui se nouent autour de leur expérience. Dans certains cas, les témoignages versent dans une surenchère dramatique et misérabiliste, mettant en scène une victimisation, voire une contrition des migrants. Cette dimension instrumentale, qu'elle soit subie ou assumée par les migrants, a été vivement dénoncée, notamment par des membres du réseau Migreurop.

Même si les témoignages adoptent un registre victimaire, ils constituent une prise de parole. Au micro, les migrants ont souvent cherché à rappeler la singularité de leur expérience migratoire et de leur trajectoire biographique. Un exercice identitaire de revalorisation de soi qui vise aussi à rendre visibles et audibles des individus qui ont le sentiment d'être oubliés ou noyés dans une masse de récits et d'acteurs. Les témoignages, enfin, ont pu prêter le flanc à des actes plus protestataires : participation à la marche pour la liberté de circulation, montée au micro pour dénoncer "une société civile de séminaires", contestation de la légitimité de certains porte-paroles, interpellelation les pouvoirs publics.

\section{Penser global, agir transnational : articulation et innovation comme maîtres mots}

9 La pluralité, et parfois l'irréductibilité, des positions citées engendrent la dispersion des acteurs, le saupoudrage de leurs actions, et in fine une division du travail militant : aux syndicats, la défense des droits des travailleurs migrants, aux organisations professionnelles de pêche, la réinsertion des "pêcheurs-passeurs" ou la dénonciation des Accords de partenariat économique, aux associations confessionnelles et collectifs de soutien, l'accueil et l'aide aux migrants, etc.

Dès lors, les assemblées de convergence ont souligné la nécessité de mieux articulerles mobilisations et d'adopter une approche systémique des migrations. Les propositions ont voulu porter sur des actions concertées, innovantes et transnationales : journées d'action globale (mobilisation le 18 décembre, Journée internationale des migrants), soutien au passeport de citoyenneté universelle, promotion de la Charte mondiale des migrants, boycott de produits ("les fraises des travailleurs agricoles migrants"), plaidoyer à de nouvelles échelles (Nations unies et CEDEAO). Ces propositions reflètent les enjeux plus globaux qui ont traversé ce FSM, à savoir les stratégies à déployer contre la routinisation de la "forme" forum et les prolongements politiques à donner aux mobilisations sociales. Le débat ouvert, rendez-vous a été pris pour la troisième conférence ministérielle euro-africaine qui aura lieu en novembre 2011 à Dakar. 


\section{AUTEUR}

\section{EMMANUELLE BOUILLY}

Doctorante en science politique au CESSP, université Paris-1 